\title{
Epidemiology of Congenital Heart Defects (CHD): Results from a Prospective, Population-Based Cohort Study (EPICARD)
}

\section{Nathalie Lelong $^{1^{*}}$, François Goffinet ${ }^{1,2}$, Babak Khoshnood ${ }^{1}$ and EPICARD Study Group}

${ }^{1}$ INSERM UMR 1153, Obstetrical, Perinatal and Pediatric Epidemiology Research Team (EPOPé), Center for Epidemiology and Statistics, Sorbonne Paris Cité (CRESS), DHU Risks in Pregnancy, Paris Descartes University, Paris, France

${ }^{2}$ Maternité de Port-Royal, Groupe Hospitalier Cochin-Broca-Hôtel Dieu, Université Paris Descartes, Assistance Publique-Hôpitaux de Paris, 53 av. de I'Observatoire, 75014 Paris, France

"Corresponding author: Nathalie Lelong, INSERM UMR 1153, Obstetrical, Perinatal and Pediatric Epidemiology Research Team (EPOPé), Center for Epidemiology and Statistics, 53 av. de l'Observatoire, 75014 Paris, France; Tel: +33142 34 5587; E-mail: nathalie.lelong@inserm.fr

Received date: March 17, 2017; Accepted date: May 03, 2017; Published date: May 09, 2017

Copyright: (c) 2017 Lelong N, et al. This is an open-access article distributed under the terms of the Creative Commons Attribution License, which permits unrestricted use, distribution, and reproduction in any medium, provided the original author and source are credited.

\begin{abstract}
The purpose of this article is to provide a summary of the initial, published results of a large, prospective, population-based cohort study of children with structural congenital heart defects in France. We also discuss the current and future work to be done in this study.
\end{abstract}

Keywords: Congenital heart defects; Epidemiology

\section{Introduction}

With a total prevalence of $1 \%$, Congenital Heart Defects (CHD) is the most common group of malformations [1-5]. CHD comprise approximately half of all deaths due to congenital anomalies [6,7]; the latter have become one of the principal causes of infant mortality in high-resource countries. In addition, despite important advances in diagnosis and clinical care of CHD [8-10], substantial risks for cardiac and general morbidity as well as long-term adverse neurodevelopmental outcomes are associated with CHD [11-18]. Most of the literature on the medical and surgical care, as well as outcomes of are based on data from referral centers [12,15,16,19-22]. However, population-based studies including all cases in a geographicallydefined population are needed to assess outcomes of CHD while avoiding the recruitment bias of hospital series. Population-based studies also allow unbiased estimates of the effects of prognostic factors such as prenatal diagnosis of CHD. Such epidemiologic studies data have been relatively rare and the existing data have important limitations, such as inadequate characterization of different groups of CHD $[5,10,19,23]$.

\section{EPICARD (Epidemiology of Children or Fetuses with Congenital Heart Defects) Study}

EPICARD was a population-based, prospective cohort study of short and long-term outcomes of new-borns with a structural CHD. The population base for the study included all births to women in the Greater Paris area (Paris and its surrounding suburbs) area between May 1, 2005 and April 30, 2008. All CHD in Live births, terminations of pregnancy for fetal anomaly (TOPFA) and fetal deaths $\geq 20$ weeks diagnosed in the prenatal period or up to 1 year of age were included in the study. Exclusion criteria included patent ductus arteriosus and patent foramen ovalae, as well as, cardiac tumors, cardiomyopathy (without structural CHD) and arrhythmias.
Data were collected from maternity units, pediatric cardiology, centers for cardiac surgery, fetal and neonatal pathology departments, neonatal and pediatric intensive care units, pediatric services and outpatient clinics in Greater Paris and neighboring tertiary care centers.

Informed consent was obtained from study participants, and the study was approved by the CNIL (French National Committee of information and Liberty). Follow-up of children in the EPICARD included assessments at one, 31/2 and eight years of age.

\section{Coding and Classification of CHD}

Two paediatric cardiologists in the EPICARD study group coded each case with one, or in less than $20 \%$ of cases, two or more six-digit codes of the International Paediatric and Congenital Cardiac Code (IPCCC) $[24,25]$. Each case was then classified into one of the ten main categories of the Anatomic and Clinical Classification of CHD, ACCCHD [24]; the latter is based on a multi-dimensional approach including criteria based on anatomy, echocardiography, clinical and surgical management of CHD. ACC-CHD includes ten main categories, ordered in accordance with the direction of blood flow and 23 subcategories. It is designed to use the codes of IPCCC but can accommodate ICD10.

\section{Outcomes and Predictor Variables}

The major outcomes of interest include prevalence, mortality, morbidity (cardiac and more general morbidity), and long-term cardiac, respiratory and neurodevelopmental outcomes. The predictive variables examined include risk factors for $\mathrm{CHD}$, notably assisted reproductive technologies, timing of diagnosis (prenatal vs. post-natal, including "late" postnatal diagnosis), type of $\mathrm{CHD}$ and clinical characteristics, including medical management, preoperative status, type of surgery and postoperative status. Supplementary clinical characteristics (gestational age, birth weight and Apgar score) are evaluated both as early outcome variables and as potential confounding variables (for example in studies looking at postoperative and more generally infant mortality). In addition, we look at the 
Page 2 of 4

predictive ability of existing surgical risk or complexity, RACHS-1 [26] and Aristotle [27], respectively. We also aim to develop alternative scores that may have greater predictive ability, including for children who do not undergo surgery. Finally, we assess the role of socioeconomic factors and place of residence in outcomes of CHD.

\section{Study Population}

The total number of live+still-births in the study population base were 317,538 , including 314,022 live births. The total number of CHD cases was 2867, including 2348 live births (82\%), 466 TOPFA (16.2\%) and 53 fetal deaths (1.8\%).

\section{Results}

In this section, we will briefly summarize some of the published results of the EPICARD study over the past five years.

\section{Prevalence, timing of diagnosis and mortality of new-borns with CHD}

In this study, we examined the prevalence, pre- and post-natal diagnosis, and infant mortality of CHD. The total prevalence of $\mathrm{CHD}$ was 90 and that of live births 78 per 10,000 births. After exclusion of Ventricular septal defects (VSD), 40\% of CHD not associated with chromosomal or other anomalies was diagnosed prenatally and approximately $30 \%$ within the first week of life. Nevertheless, $20 \%$ of "isolated" CHD with VSD excluded was diagnosed after the fourth week of life. Infant mortality of "isolated" CHD, excluding VSD was $8.5 \%$ and $40 \%$ of deaths occurred after the fourth week of life. Pre- vs. post-natal diagnosis, proportions of TOPFA and risk of infant mortality varied substantially across the categories of ACC-CHD, suggesting that it may be a useful measure of severity and hence predictor of outcomes of CHD [28].

\section{Risk of preterm births for new-borns with CHD}

Preterm birth (PTB) and CHD are two major causes of mortality and disability of perinatal origin. There are however limited data on the association between risk of preterm births (PTB) for new-borns with $\mathrm{CHD}$; this is particularly the case regarding population-based studies of CHD and PTB. We conducted a population-based study to look at the risk of PTB in new-borns with CHD [29]. We also assessed differential risks of $\mathrm{CHD}$ for different categories of $\mathrm{CHD}$, using the ACC-CHD ten main categories.

We found that $13.5 \%$ of the new-borns with CHD were PTB. The odds of PTB were twice as high as that in the general population (Odds ratio 2.0, 95\% CI, 1.6-2.5). This increased risk of PTB was essentially limited to an increase in spontaneous PTB for new-borns with CHD. In contrast, we found no increased risk related to medical induced PTB. The higher risk of PTB associated with CHD persisted after exclusion of chromosomal or other anomalies. We also found substantial variations in risk of PTB across the categories of CHD, which persisted after adjustment for known risk factors of PTB and factors related to medical management of pregnancy and delivery. We concluded that our finding may be helpful for generating hypotheses about common underlying developmental mechanisms for CHD and PTB [29].

\section{Assisted reproductive technologies (ART) as a specific risk factor of $\mathrm{CHD}$}

Using data from the Paris Registry of Congenital Malformations and the EPICARD study, we assessed the risk of CHD for fetuses conceived after ART [30-32]. We used a case-control design with malformed controls. In the first study, we looked at the association between ART and overall risk of CHD as well as for different categories of CHD. Assisted reproductive technologies included inductors of ovulation only, in vitro fertilization, and intracytoplasmic sperm injection. Overall, a higher proportion of cases were exposed to ART as compared with controls ( 4.7 vs. $3.6 \%, \mathrm{p}=0.008)$ and was associated with a $40 \%$ increase in the Maternal age, socioeconomic factors, and year of birth-adjusted odds of $\mathrm{CHD}$ without chromosomal abnormalities was $40 \%$ higher than controls [Adjusted odds ratio (OR) 1.4, 95\% CI 1.1-1.7]. There were specific associations between assisted reproductive technologies and odds of malformations of the outflow tracts and ventriculoarterial connections (adjusted OR 1.7, 95\% CI 1.2-2.4) and of cardiac neural crest defects and double outlet right ventricle (adjusted OR 1.7, 95\% CI 1.1-2.7).

In a second study, we assessed whether there were higher odds of four selected CHD (hypoplastic left heart syndrome, transposition of great arteries, tetralogy of Fallot (TOF) and coarctation of the aorta) in infants conceived by ART. We found that a higher proportion of cases with TOPF were conceived following ART as compared with controls (6.6 versus $3.5 \%, \mathrm{p}=0.002$ ); this was not however the case for the other three CHDs. ART (all methods combined) was associated with a 2.4fold higher odds of TOF after adjustment for maternal characteristics, paternal age and year of birth [Adjusted OR, 2.4, 95\% CI, 1.5-3.7]; the specific odds of TOF in relation to in vitro fertilization with intracytoplasmic sperm injection (ICSI) was three-fold higher than controls (Adjusted OR, 3.0, 95\% CI, 1.0-8.9). In contrast, we did not find any statistically significant associations between ART and transposition of great arteries; hypoplastic left heart syndrome and coarctation of aorta. We concluded that the developmental basis of the specific association between the risk of TOF and ART, in particular the possible implication of neural crest cells merits to be further investigated.

Finally, in a third study, we assessed the extent to which the previous association found between ART and risk of TOF may be mediated by the multiple pregnancies, more frequent in pregnancies conceived after ART. We used a path-analysis model using a counterfactual approach to decompose the total effect of ART into an indirect (that mediated by the association between ART and multiple pregnancies) and a direct effect. We found that most (79\%) of the effect associated with ART was a direct effect (i.e., not mediated by multiple pregnancies), whereas $21 \%$ of the effect was indirect (i.e., due to multiple pregnancies). Overall, ICSI was associated with a 3.5-fold higher odd of TOF (Adjusted OR 3.5, 95\% CI, 1.1-11.2); 11\% of this effect was indirect (mediated through multiple pregnancies). Hence, by far most of the higher risk of TOF associated with ART was a direct effect and only a small proportion of the effect, particularly in case of ICSI mediated by multiple pregnancies.

\section{Socioeconomic disparities in health care are not inevitable: $\mathrm{A}$ population-based study of prenatal diagnosis of congenital heart defects.}

In this study, our main objective was to assess socioeconomic differences in the probability of prenatal diagnosis of CHD; we also 
looked at disparities in Termination of Pregnancy for Foetal Anomaly (TOPFA). We found that $29.1 \%$ (95\% CI, 27.5-30.1) of all cases were prenatally diagnosed. The proportion of CHD prenatally diagnosed was comparable across categories of maternal occupation, geographic origin and place of residence. In contrast, we found important differences in the probability of TOPFA by maternal geographic origin; for maternal occupation and place of residence however, differences were smaller and not statistically significant. We concluded that our result show that with an appropriate health system organization that provides reimbursed specialized services, access to prenatal diagnosis can be assured for all socioeconomic groups [33]. Differences we found in TOPFA across maternal geographic origins may reflect women's preferences that should be respected. Nevertheless, these differences imply that families with fewer resources may become disproportionately responsible for care of children with severe CHD.

\section{Future Work}

We have recently completed the follow-up of the children in the cohort at 8 years of age. Follow-up at age 8 included a complete cardiac, neurological, and general pediatric examination as well as an evaluation of the children's respiratory and neurodevelopmental outcomes, using standardized instruments (K-ABC 2and NEPSY II). In addition, parents were asked for information about their children's behavior and school situation. We have thus obtained important data about their outcomes at a key age. This follow-up at age 8 of the children of the cohort is very useful as the literature on the follow-up of children at high risk shows that longer follow-up periods are essential for assessing their outcomes. Indeed, the initial or early assessments do not always reflect the longer term outcomes of children at high risk (for example, preterm infants) [34-36]. This is particularly true for the children who undergo surgery several times in early childhood. The data at age 8 complement those collected at age $31 / 2$ and will help us better understand the changes in outcomes over time and to identify the prognostic factors of short- and long-term outcomes of CHD.

\section{References}

1. Hoffman JI (1995) Incidence of congenital heart disease: II Prenatal incidence. Pediatr Cardiol 16: 155-165.

2. Hoffman JI, Kaplan S (2002) The incidence of congenital heart disease. J Am Coll Cardiol 39: 1890-1900.

3. Dolk H, Loane MA, Abramsky L, de Walle H, Garne E (2010) Birth prevalence of congenital heart disease. Epidemiology 21: 275-277.

4. EUROCAT Central Registry UoU (2009). EUROCAT special report: Congenital heart defects in Europe, 2000-2005.

5. Dolk H, Loane M, Garne E; European Surveillance of Congenital Anomalies (EUROCAT) Working Group (2011) Congenital heart defects in Europe: Prevalence and perinatal mortality, 2000 to 2005. Circulation 123: 841-849.

6. Lee K, Khoshnood B, Chen L, Wall SN, Cromie WJ, et al. (2001) Infant mortality from congenital malformations in the United States, 1970-1997. Obstet Gynecol 98: 620-627.

7. Hatton F, Bouvier-Colle MH, Blondel B, Pequignot F, Letoullec A (2000) Trends in infant mortality in France: frequency and causes from 1950 to 1997. Arch Pediatr 7: 489-500.

8. Allan LD (2000) The outcome of fetal congenital heart disease. Semin Perinatol 24: 380-384.

9. Bonnet D, Coltri A, Butera G, Fermont L, Le Bidois J, et al. (1999) Detection of transposition of the great arteries in fetuses reduces neonatal morbidity and mortality. Circulation 99: 916-918.
10. Khoshnood B, De VC, Vodovar V, Goujard J, Lhomme A, et al. (2005) Trends in prenatal diagnosis, pregnancy termination and perinatal mortality of new-borns with congenital heart disease in France, 1983-2000: A population-based evaluation. Pediatrics 115: 95-101.

11. Ikle L, Hale K, Fashaw L, Boucek M, Rosenberg AA (2003) Developmental outcome of patients with hypoplastic left heart syndrome treated with heart transplantation. J Pediatr 142: 20-25.

12. Limperopoulos C, Majnemer A, Shevell MI, Rosenblatt B, Rohlicek C, et al. (2000) Neurodevelopmental status of new-borns and infants with congenital heart defects before and after open heart surgery. J Pediatr137: 638-645.

13. Limperopoulos C, Majnemer A, Shevell MI, Rosenblatt B, Rohlicek C, et al. (2001) Functional limitations in young children with congenital heart defects after cardiac surgery. Pediatrics 108: 1325-1331.

14. Limperopoulos C, Majnemer A, Shevell MI, Rohlicek C, Rosenblatt B, et al. (2002) Predictors of developmental disabilities after open heart surgery in young children with congenital heart defects. J Pediatr 141: 51-58.

15. Wernovsky G, Newburger J (2003) Neurologic and developmental morbidity in children with complex congenital heart disease. J Pediatr 142: 6-8.

16. Wernovsky G, Shillingford AJ, Gaynor JW (2005) Central nervous system outcomes in children with complex congenital heart disease. Curr Opin Cardiol 20: 94-99.

17. Bacha EA, Larrazabal LA, Pigula FA, Gauvreau K, Jenkins KJ, et al. (2008) Measurement of technical performance in surgery for congenital heart disease: the stage I Norwood procedure. J Thorac Cardiovasc Surg 136: 993-997.

18. Curzon CL, Milford-Beland S, Li JS, O'Brien SM, Jacobs JP, et al. (2008) Cardiac surgery in infants with low birth weight is associated with increased mortality: Analysis of the Society of Thoracic Surgeons Congenital Heart Database. J Thorac Cardiovasc Surg 135: 546-551.

19. Meberg A, Otterstad JE, Frøland G, Lindberg H, Sørland SJ (2000) Outcome of congenital heart defects--a population-based study. Acta Paediatr 89: 1344-1351.

20. Majnemer A, Limperopoulos C (2002) Importance of outcome determination in pediatric rehabilitation. Dev Med Child Neurol 44: 773-777.

21. Majnemer A, Limperopoulos C, Shevell M, Rosenblatt B, Rohlicek C, et al. (2006) Long-term neuromotor outcome at school entry of infants with congenital heart defects requiring open-heart surgery. J Pediatr 148: 72-77.

22. Majnemer A, Limperopoulos C, Shevell M, Rohlicek C, Rosenblatt B, et al. (2006) Health and well-being of children with congenital cardiac malformations and their families, following open-heart surgery. Cardiol Young 16: 157-164.

23. Blyth M, Howe D, Gnanapragasam J, Wellesley D (2008) The hidden mortality of transposition of the great arteries and survival advantage provided by prenatal diagnosis. BJOG 115: 1096-1100.

24. Houyel L, Khoshnood B, Anderson RH, Lelong N, Thieulin AC, et al. (2011) Population-based evaluation of a suggested anatomic and clinical classification of congenital heart defects based on the International Paediatric and Congenital Cardiac Code. Orphanet J Rare Dis 6: 64.

25. Franklin RC, Jacobs JP, Krogmann ON, Béland MJ, Aiello VD, et al. (2008) Nomenclature for congenital and paediatric cardiac disease: Historical perspectives and The International Pediatric and Congenital Cardiac Code. Cardiol Young 2: 70-80.

26. Jenkins KJ (2004) Risk adjustment for congenital heart surgery: the RACHS-1 method. Semin Thorac Cardiovasc Surg Pediatr Card Surg Annu 7: 180-184.

27. Jacobs JP, Maruszewski B, Kurosawa H, Jacobs ML, Mavroudis C, et al. (2010) Congenital heart surgery databases around the world: do we need a global database? Semin Thorac Cardiovasc Surg Pediatr Card Surg Annu 13: 3-19.

28. Khoshnood B, Lelong N, Houyel L, Thieulin AC, Jouannic JM, et al. (2012) Prevalence, timing of diagnosis and mortality of new-borns with congenital heart defects: A population-based study. Heart 98: 1667-1673. 
Citation: Lelong N, Goffinet F, Khoshnood B, EPICARD Study Group (2017) Epidemiology of Congenital Heart Defects (CHD): Results from a Prospective, Population-Based Cohort Study (EPICARD). J Neonatal Biol 6: 253. doi:10.4172/2167-0897.1000253

Page 4 of 4

29. Laas E, Lelong N, Thieulin AC, Houyel L, Bonnet D, et al. (2012) Preterm birth and congenital heart defects: a population-based study. Pediatrics 130: e829-837.

30. Tararbit K, Houyel L, Bonnet D, De Vigan C, Lelong N, et al. (2011) Risk of congenital heart defects associated with assisted reproductive technologies: A population-based evaluation. Eur Heart J 32: 500-508.

31. Tararbit K, Lelong N, Thieulin AC, Houyel L, Bonnet D, et al. (2013) The risk for four specific congenital heart defects associated with assisted reproductive techniques: A population-based evaluation. Hum Reprod 28: 367-374.

32. Tararbit K, Lelong N, Houyel L, Bonnet D, Goffinet F, Khoshnood B (2014) Assessing the role of multiple pregnancies in the association between tetralogy of Fallot and assisted reproductive techniques: A pathanalysis approach. Orphanet J Rare Dis 9: 27.
33. Khoshnood B, Lelong N, Andrieu T, Houyel L, Bonnet D, et al. Assessing sociodemographic differences (or lack thereof) in prenatal diagnosis of congenital heart defects: A population-based study. BMJ Open 6: e009353.

34. Largo RH, Graf S, Kundu S, Hunziker U, Molinari L (1990) Predicting developmental outcome at school age from infant tests of normal, at-risk and retarded infants. Dev Med Child Neurol 32: 30-45.

35. Latal B (2009) Prediction of neurodevelopmental outcome after preterm birth. Pediatr Neurol 40: 413-419.

36. Voss W, Neubauer AP, Wachtendorf M, Verhey JF, Kattner E (2007) Neurodevelopmental outcome in extremely low birth weight infants: What is the minimum age for reliable developmental prognosis? Acta Paediatr 96: 342-347. 